\title{
VIRTUAL CLASS - AN APPROPRIATE ENVIRONMENT FOR DISTANCE LEARNING MATHEMATICS AT AN OPEN UNIVERSITY
}

\author{
Maria Hadjinicolaou, [hadjinicolaon@eap.or], Hellenic Open University, 11 Sabtouri Str.Patras, GR-26222, \\ Greece, [www.eap.gr]
}

\begin{abstract}
Distance learning at an Open University usually engages technology mediated teaching tools and learning environments that have been designed and developed during the last decades. Unlike the apparently governing social learning pedagogical point of view and the benefits of asynchronous e-learning platforms, the cognitive perspectives of education and the need for synchronous interaction between the tutor and the students as well as the students themselves, is decisive for the quality of attained knowledge. Open universities, traditionally, used to organize consultative group meetings aiming at the better understanding of concepts, the development of skills, the gaining of positive attitudes and finally the enhancement of knowledge. Tutors in mathematics courses face significant difficulties due to the students' heterogeneous mathematical background and thus problems arise that may impede a lot the acquisition of knowledge. These problems must be also addressed in the group meetings and therefore the reconstruction of the pre-existing mathematical knowledge under a common basis and the acquisition of cognitive flexibility in handling mathematical concepts in different fields are two fundamental objectives of such meetings. Virtual classes provide the appropriate environment for achieving these aims, since they allow a qualitative dynamical, on-line communication among the members of a group.
\end{abstract}

Keywords: virtual class, distance learning, teaching mathematics, online teaching, synchronous education, Open University.

\section{Introduction}

In open education systems, "teaching" mathematics at graduate level via distance educational methodology presents difficulties mostly due to the students' variable mathematical background. This diversity is a consequence of the enrolment procedure of the Open University which does not involve any student pre-selection mechanisms. Students come from different social and learning environments and their relationship with mathematics has begun at an earlier time than that of students of conventional universities (Artigue, 1999). It is observed that beyond a possible common "vocabulary" and perhaps the similarity of techniques, their approach and the conception for common mathematical objects, such as the limit, derivative, integral, etc. are different and also deviate from the aims of a course in mathematics at the university level. These problems are also encountered in conventional universities (Chevallard, 1992), but they are less pronounced.

Another type of difficulty is that the acquired knowledge is fragmented. This means that it is closely connected with the educational situation out of which it resulted and beyond this, very little can be used. This is a well-known phenomenon and a way to amend it is to create another 
educational situation, which will be a common ground between the tutor and the student in order to reformulate this knowledge within a new context. In distance education systems, these difficulties may be resolved during the meetings between the tutors and the tutees, the so called Common Advisory Meetings (O.S.S) (Kokkos \& Lionarakis, 1998; Hadjinicolaou, 2001). These take place at regular time intervals and play a catalytic role towards two basic directions. One side is "therapeutic", where training problems are addressed and psychological support is given. The other side is "progressive", which concerns with the enhancement of the acquired knowledge and also with the development of a critical way of thinking and fostering flexibility in handling mathematical concepts in different fields.

With respect to the learning processes, the prevailing view of the open and distance education seems to line with that of Brousseau (1997) and the theory of "teaching situations". According to this, learning is a process of adaptation, in the biological sense, based on the assimilation of the "new" and the accommodation, where the "new" contradicts and causes cognitive conflict, with the already obtained knowledge.

This interpretation of the concept of "learning" is based on the work of Piaget and constitutes the constructivist approach. However the process of adaptation - learning during an educational situation is not only of mathematic nature. The student is adjusted towards mathematical knowledge but he is also adapted to the teaching system, the rules and norms, as well as making assumptions about the expectations of the tutor - what Brousseau (1997) identified as a "didactic contract". But very often there can be a thoroughly versatile student that can succeed mainly because he learned to decode the terms of the educational contract and respond to them, rather than because he "learned mathematics". The control of this qualitative difference is very hard to be accomplished, particularly in a distance education system in which the student is studying alone (Keegan, 1986; Holmberg, 1995), and opportunities to assess his knowledge or to face a cognitive conflict is very limited. Such opportunities-educational situations have to be initiated by the tutors during the group meeting O.S.S.. Traditionally, these meetings were physical, but with the advances in educational technology and especially those regarding the e-learning and the online courses, these meetings can be also taken place virtually through a virtual class. Much effort has been put and useful powerful software packages and technology mediated environments are available that make communication more interactive and collaborative. Many studies discuss the usefulness and these ICT innovations have brought in the Open and Distance Learning philosophy and methodology. See for example Rovai (2002), while discussion on the use of Computer Mediated Communication (CMC) platforms and the Computer Supported Collaborative Learning environments (CSCL) to the fostering of collaborative learning can be found in Schellens and Valcke (2006) and Strijbos and Fischer (2007). Yun Lu (2011) presented as study on the use of the ICT tools: Wimba and MyMathLab, in a virtual classroom, for teaching online a mathematics course. Gleason (2006) describes the outcomes from the employment the Centra platform for teaching mathematics online. In this manuscript we expand further on the utility of a virtual class by considering it as the "ground" for reconstruction of mathematical concepts and the developing cognitive flexibility.

\section{Case study}

In order to illustrate the above mentioned arguments, we present a case study that concerns the reconstruction of the concept of the integral which was elaborated during a Group meeting (OSS) that took place through a virtual class platform. The reconstruction aims in the deepening and expanding of the concept of the integration and the integral. These mathematic objects had already been taught at the end of high school through the concept of indefinite integrals by means of the inverse process of derivation. However, the calculation of simple areas and volumes 
is performed mostly mechanistically or it is based on the intuition. At the university level, the theory of integration is introduced through the Riemann integral and at more advanced levels, through the Lebesgue integral. The process that was followed, was the same with the one adopted in a physical meeting (Hadjinicolaou, 2001).

\section{Formulation of the Problem -Educational objectives}

The scenario assumes a distance learning system and moreover the first year of undergraduate study of the mathematical module "Calculus".

Communicating with students, the following problem was revealed: Most students, while being able to formulate mathematical definitions and describe the properties of integrals, they have acquired considerable skill in dealing with specific types of problems and particularly to perform calculations, rather than the deepening on the relevant concept and the applicability in different cases. In other words, they are able to solve several exercises applying the suggested methods and techniques, but when they have to decide whether to apply the process of integration for a particular problem, they cannot answer. In order to proceed, they are looking for standard linguistic indications in the statement of the problem, which they are familiar with and have learned to recognize (e.g. elementary area, or work force, or power, etc.). This is a problem also observed in "conventional" universities (Artigue, 1999)

In regard to the distance education system, a fundamental factor for achieving the objectives at the cognitive level, is the cultivation of confidence on the students' abilities and also of the effectiveness of the system of open and distance learning and technically, of the quality of communication through the virtual class platform.

"Integration" is frequently encountered in mathematics and physical sciences and therefore a very deep and accurate knowledge is required. The aim, with respect to the educational object, is the comprehension and the deepening into the concept and the process of integration, as well as the development of the ability in recognizing whether a problem implies integration. This way the students will acquire skills in solving complicated mathematical problems, sharpen their judgment and acquire mathematical thinking.

The task given to the students aims additionally in the acquisition of positive attitude, the reinforcement of their self-confidence and self-respect, the cancelling of any hesitations, phobias and negativism, as they are exposed for the first time in a class to deal with a rather no- trivial mathematical problem.

According to the preceding description, the educational objectives of a group meeting via a virtual class (V.O.S.S.) was set with respect to the level of knowledge, skills and attitudes. Based on these objectives the outcomes of the (V.O.S.S) will be assessed.

\section{Schedule of the V.O.S.S.}

The designing of basic stages of the V.O.S.S. includes the determination for each stage of the following: a) the content, b) aims and objectives, c) educational techniques, and d) familiarization with the virtual class platform, and other ICT tools that will be used (Kokkos \& Lionarakis, 1998), It is worth mentioning here, that an analogous case study had been performed in a physical meeting OSS examining the same problem (Hadjinicolaou, 2001).

Due to the technology evolution and its adaptation in distance learning systems, the physical presence of the students in the group meetings is not necessary any longer. Online learning becomes more attractive, although its effectiveness is still a subject under consideration.

European Journal of Open, Distance and e-Learning - Vol. 17 / No. 1 
Within this context, in the present case study, we also examine the influence of the use of the virtual class platform to the whole procedure.

Table 1: Educational objectives-stages

\begin{tabular}{|l|l|l|l|l|}
\hline $\begin{array}{l}\text { Educational } \\
\text { objectives: }\end{array}$ & Stage 1 & Stage 2 & Stage 3 & Stage 4 \\
\hline$\alpha)$ knowledge & & $\begin{array}{l}\text { Formulation } \\
\text { and analysis of } \\
\text { the problem } \\
\text { Identification of } \\
\text { the concept }\end{array}$ & $\begin{array}{l}\text { Detailed and in } \\
\text { depth } \\
\text { comparative } \\
\text { study }\end{array}$ & $\begin{array}{l}\text { Conception and } \\
\text { mathematical } \\
\text { formulation of } \\
\text { similar problems. }\end{array}$ \\
\hline$\beta$ skills & $\begin{array}{l}\text { Ability in } \\
\text { identification } \\
\text { and } \\
\text { mathematical } \\
\text { description of } \\
\text { the concept }\end{array}$ & $\begin{array}{l}\text { Development of } \\
\text { skills in problem } \\
\text { solving }\end{array}$ & $\begin{array}{l}\text { Skills in the } \\
\text { appropriate use of } \\
\text { the concept and } \\
\text { Cognitive flexibility }\end{array}$ \\
\hline v) attitudes & $\begin{array}{l}\text { Cultivation of } \\
\text { positivism, } \\
\text { encouragement } \\
\text { Decrease } \\
\text { negativism }\end{array}$ & $\begin{array}{l}\text { Critical } \\
\text { analytical } \\
\text { thinking } \\
\text { Reinforcement } \\
\text { of initiatives }\end{array}$ & $\begin{array}{l}\text { Positive and } \\
\text { creative } \\
\text { behaviour , } \\
\text { conceptual } \\
\text { embedding of the } \\
\text { particular } \\
\text { mathematical } \\
\text { object }\end{array}$ & $\begin{array}{l}\text { Self-respect } \\
\text { Optimist thinking of } \\
\text { following context }\end{array}$ \\
& & &
\end{tabular}

\section{Time schedule of the stages}

\section{Stage 1}

At the first stage, we spend approximately 20 minutes so that the students feel comfortable in using the platform, and answering questions regarding ODL, or resolving technical, institutional and organizational issues. Students feel more secure. A friendly atmosphere is growing along with a positive attitude and will for continuing the meeting.

\section{Stage 2}

It lasts 45 minutes approximately and it involves the identification of the concept of integration through a physics problem and the description of its features.

The proposed teaching methods are: case study, brain-storming, questions and answers, all of them help in forming positive attitudes. This way, we encourage the freely expression of ideas, and the dialogue among the members of the group. Furthermore, the critical and analytical way of thought is also cultivated.

The educational tools that are used, are the power point slides, writing pad, whiteboard and besides, files containing the description of the problem that have been uploaded for downloading by the students. The students, divided in small groups of two or three, located in 9 different places over the country, are communicating via the virtual class platform. 


\section{The example}

The problem that is presented in the students is the following:

Given a rod of length $L$ meters, negligible thickness and weight $M \mathrm{~kg}$. At a distance $A$ meters from one edge and in the same direction, a mass of weight $m \mathrm{~kg}$ is placed, as it is shown below. Find the value of the force that is developed between two masses.

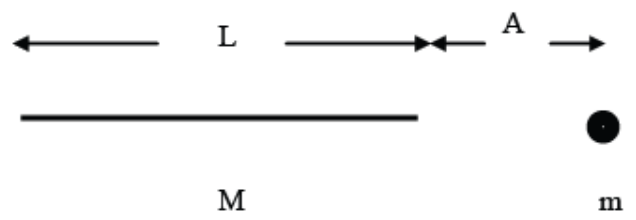

Figure 1. Calculation of the force

When the problem is placed without linguistic indications, the students cannot identify that it is a problem of integration. However they do not remain inactive and apply a technique that is often used in the physics: They consider the mass of the rod concentrated in the centre and apply the law of Newton for these two masses. This answer was given by many students.

However in a group of 25 students, some of them start to wonder whether the law can be applied in this case! A way of checking the validity of this result is the calculation through another procedure. Thus some students propose that the rod should be cut in the middle and apply the law in each one of the two pieces separately. Naturally this process gives different result from the initial calculation and thus it is realised that the law cannot be applied in the particular case.

Unlike this negative answer for the solution of the problem, it is positive for the continuation of the didactic situation, since the students noted the fundamental principle:

"The contribution of each piece of the rod in the value of the force depends on the distance of this piece from the mass $m$ "

This ascertainment gives rise to the statement: In order to calculate the value of the force that is developed between the rod and the specific mass, the bar should be cut in small pieces (so that they can be considered point wise), and for each one of them, the force that is developed due to the mass $m$, must be calculated with respect to the distance from each one of this. The total force will be the sum of the individual forces. What is described however is not other than the concept of the integration and the students were guided to discover it:

"The summation by a continuous way is the integration"

The designing of this example was based on a similar one proposed by Legrand, that was first presented in Artigue (1999) and constitutes the starting line for the reconstruction of the concept of integration.

It should be noted that the scenario described above, prerequisites a student group, since the initial strategy turned out to be erroneous through the discussion among the members of the group and the team "game" helped in the finding of solution at a reasonable period of time. The result matches to the one obtained in the physical meeting in a classroom, but it would be not the same if the particular problem would be delivered individually to the students, or even if it was delivered to a group of students of the size of a conventional university classroom (approx.80). The outcome would be quite different in the case where the same problem would be presented to 
the students by the tutor. It is the group dynamic that makes this finding procedure functional and effective and it is the dynamic situation created that can be perfectly adjusted to the environment of a virtual class.

\section{Stage 3}

The objective at this stage is the deepening in the analysis of a problem and the search construction of a solution. Students have to work with different type of problems that can be solved following the same procedure of integration. Then, they are encouraged to look upon their solution and discuss the existing correlations and similarities among the problems aiming to make integration a useful mathematical tool. For this purpose we distribute per group a hand out with problems and we ask students to identify whether each problem describes an integration process, presenting his arguments to the others. This way the objective of reconstruction of knowledge has been achieved.

After this stage, the students seem to have assimilated the concept of integration, which now has formed into a mathematical object and thus can be used in more complicated cases. In the following, the students work within their small teams and are practicing by solving similar problems selected appropriately by the tutor. At the end, the students may upload and present their solutions and discuss the obtained results. This way, the objectives set initially have been accomplished. Through this exercise, students have the ability to work together communicate and collaborate and thus to develop relevant skills and adopt positive attitudes, as it is described in the table1.The educational technique of working in small groups was chosen because it strengthens collaboration; it creates a friendly atmosphere, and equips students with solving skills. The plenary presentation allows the students to employ various ways for expressing the concept and enables the proper application of techniques for solving similar problems.

\section{Stage 4}

At this stage which is programmed to last 40 minutes, the students practice in the "construction" of examples and therefore, they develop creative skills on the use of the concept that was studied. Regarding the attitudes, the successful outcome of this phase 4 is expected to give satisfaction to the students and thereby boosting self-esteem and self-confidence, which constitute an important arsenal for the continuation of their studies.

The assessment of the meeting the objectives at each stage is performed by the tutor and the students themselves.

\section{Conclusions}

In open and distance learning of Mathematics at graduate level, there are two didactic processes of fundamental importance. These are the reconstruction of mathematical objects and the cultivation of cognitive flexibility in their use. A case study focused on the reconstruction of the mathematical object of the "integration" was presented. Furthermore it was showed that the use of a virtual class platform provides the necessary environment for this educational procedure gaining beneficial results. The virtual class resembles the environment of the physical class, allowing a dynamic "didactic situation" to be built. This dynamic situation between the students, the tutor and the mathematical object is unique and cannot be substituted by any other online or e-learning method employing asynchronous or one-to-one online communication. Therefore we believe that virtual classes could be successfully integrated in the course design of the undergraduate maths courses of an open university. In the particular study, two platforms were employed: the "Centra", by Saba, http://centra.eap.gr and the "E-Presence" 
http://epresence.grnet.gr where the last one turned to be more preferable, since it is of HD (720p/30fps), and it does not require any ICT skills from the students.

\section{References}

1. Artigue, M. (1999). The teaching and Learning of Mathematics at the University Level. In Notices of the AMS, 46(11), (pp. 1377-1385)

2. Brousseau, G. (1997). The theory of Didactic Situations. Kluwer, Dordrecht

3. Chevallard, Y. (1992). Concepts fondamentaux de la didactique. In Recherches en Didactique des Mathematiques, (12), (pp. 73-128)

4. Gleason, J. (2006). Teaching Mathematics Online: A Virtual Classroom. In Journal of Online Mathematics and its Applications (May).

5. Hadjinicolaou, M. (2001). Reconstruction and Cognitive Flexibility, fundamental objectives of an OSS for mathematics. (In Greek). In Proceedings of the 1st Open and Distance learning Conference, May 25-27, Patras, Greece.

6. Holmberg, B. (1995). Theory and practice of distance education. Routledge, London

7. Keegan, D. (1986). The foundations of distance education. Routledge, London

8. Kokkos, A. and Lionarakis, A. (1998), Open and Distance Learning. Hellenic Open University ed., Patras

9. Rovai, A.P. (2002). Building Classroom Community at a Distance: A Case Study. In Educational Technology Research \& Development, 49(4), (pp. 33-48)

10. Schellens, T. and Valcke, M. (2006). Fostering knowledge construction in university students through asynchronous discussion groups. In Computers \& Education, 46(4), (pp. 349-370)

11. Strijbos, J.W. and Fischer, F. (2007). Methodological challenges for collaborative learning research. In Learning and Instruction, 174), (pp. 389-393)

12. Yun Lu (2011). Using a Virtual Classroom to Teach Online Mathematics. Found online at http:// files.eric.ed.gov/fulltext/ED519767.pdf 